\title{
Analysis of the optimisation of parameters for the laser machining of timber
}

\author{
Chyn-Shu Deng ${ }^{1} \cdot$ Kuo-Lun Hsia ${ }^{1}$ \\ Received: 11 April 2016/Accepted: 15 August 2016 / Published online: 25 August 2016 \\ (C) The Author(s) 2016. This article is published with open access at Springerlink.com
}

\begin{abstract}
Fuzzy-based Taguchi methods were used to optimise the parameters for the $\mathrm{CO}_{2}$ laser machining of timber. An orthogonal array, the signal-to-noise $(\mathrm{S} / \mathrm{N})$ ratio, and the analysis of variance (ANOVA) are employed with reference to process factors. Combining the Taguchi method and fuzzy logic, using the multiple performance characteristics index (MPCI), allowed determining the optimal combination of factors for cutting the timber. The confirmatory test was performed to verify the estimated response.
\end{abstract}

Keywords Taguchi methods $\cdot \mathrm{CO}_{2}$ laser machining . Signal-to-noise $\cdot$ Analysis of variance

\section{Introduction}

Lasers are often used to carve, cut drill and weld; because of their broad applicability [1], their small thermal diffusivity and its graphics can be processed by computer software design. Therefore, laser processing is worthy of being a reference method. Timber has been traditionally cut using a disc sander, jigsaw or other mechanical processes; however, these techniques are unable to cut complex shapes and are prone to tool abrasion. By contrast, using lasers to cut timber produces satisfactory results and avoids tool abrasion, but is prone to scorching. Therefore, this study applied the Taguchi method

Chyn-Shu Deng

csdeng@nuu.edu.tw

1 Department of Mechanical Engineering, National United University, 2,Lienda, Miaoli 36063, Taiwan, Republic of China to determine the optimal cutting width and depth to process timber using a laser, aiming to reduce scorching and other undesirable phenomena.

Juan Carlos et al. [2] determined that the moisture content affected the laser cutting of timber, and the timber tracheids determined the cutting direction. Panznera et al. [3] determined that when timber was cut in a conventional manner, its surface became a thin extruded layer; thus, using an $\mathrm{Nd}$ :YAG laser or a TEA-CO $\mathrm{CO}_{2}$ laser could improve this process. Lau et al. [4] provided a systematic analysis of the $\mathrm{Nd}$ :YAG laser and electric discharge machining process for processing composite materials, aiming to improve the processing efficiency. Samant and Dahotre [5] used a laserheating alloy (Ti6Al4V) to determine the cutting depth and width of the timber that was affected by the heat, and used the finite element method to perform a simulation, observing an agreement between the data of the experiment and that of the simulation. Dubey and Yadava [6] determined that laser processing was applicable to various materials, and the current $\mathrm{CO}_{2}$ and $\mathrm{Nd}$ :YAG lasers were the most stable. Hsieh et al. [7] proposed a regression analysis of the Taguchi method to improve the multiple response of the system. Lumley [8, 9] used laser machining to cut brittle, flaky material. Tsai and Chen $[10,11]$ proposed the control burst theory, in which the absorption of laser energy by the material being processed produces heat stress, which, if the temperature is below the melting point of the material, results in a temperature gradient that converts the compressive stress into tensile stress, generating cracks and, subsequently, the sliver effect.

Therefore, applying traditional optimisation methods using $\mathrm{CO}_{2}$ laser to process timber is time-consuming and expensive. By contrast, Taguchi methods require few experiments, followed by signal-to-noise $(\mathrm{S} / \mathrm{N})$ ratio and ANOVA analyses, to identify the optimal combination of factors quickly and cheaply. Therefore, this study used the Taguchi method 
combined with fuzzy logic to determine the optimal parameters for processing timber, using a $\mathrm{CO}_{2}$ laser.

\section{Laboratory equipment}

\subsection{Specimen preparation}

In this study, the timber specimen belonged to Pseudotsuga menziesii; it had a density of $540 \mathrm{~kg} / \mathrm{m}^{3}$, a specific gravity of 0.48 , a modulus of elasticity of $13,400 \mathrm{MPa}$ and a modulus of rupture of $85,000 \mathrm{MPa}$. The specimen was characterised by a structural force equivalent to that of the strongest commercial cork; it was easy to dry and difficult to crack; therefore, it was appropriate for mechanical cutting. The specimen was rectangular and had dimensions of $0.4 \mathrm{~m}$ long $\times 0.3 \mathrm{~m}$ wide $\times 0.25 \mathrm{~m}$ high, and a flat belt machine was used to polish its surface to allow the easy observation of the cutting process.

\subsection{Research equipment}

The $\mathrm{CO}_{2}$ laser equipment used in this study exhibited a maximum output power of $80 \mathrm{~W}$, model type LG1200 (Lin Ciang Technology Co., Ltd., Taiwan), a maximum processing speed of $400 \mathrm{~mm} / \mathrm{s}$ and a maximum processing range of $1200 \mathrm{~mm} \times 900 \mathrm{~mm}$. This machine can be coupled to a computer to register the two-dimensional $\mathrm{X}-\mathrm{Y}$ direction movement of the laser; together with the focus-adjustable $\mathrm{Z}$-axis position, a three-dimensional structure can be generated. The optical microscope, produced by UltraZoom included zoom lens and overlap software, was used to measure the upper cutting width and cutting depth characteristics with microscale resolution.

\section{Research methods}

\subsection{Orthogonal array experiment}

To select the most favourable combination of control factors, numerous experiments are required when many control factors and parameters are involved. However, using the L9 orthogonal array (Table 1) of the Taguchi method requires only nine experiments to determine the most favourable experimental design parameters. Table 2 lists the control factors and levels used in each experiment to test machining profile (Fig. 1); the feasible space for the control factors was defined by varying the laser power in the range $25.6 \sim 28.8 \mathrm{~W}$; the auxiliary gas was no auxiliary, air gas and nitrogen gas; the processing speed in the range $3 \sim 5 \mathrm{~mm} / \mathrm{s}$ and the number of cuts in the range $1 \sim 3$ times; three levels of the each control factors were selected.
Table 1 L9 orthogonal array

\begin{tabular}{lllll}
\hline Experiment no. & \multicolumn{4}{l}{ Control factor } \\
\cline { 2 - 5 } & A & B & C & D \\
\hline 1 & 1 & 1 & 1 & 1 \\
2 & 1 & 2 & 2 & 2 \\
3 & 1 & 3 & 3 & 3 \\
4 & 2 & 1 & 2 & 3 \\
5 & 2 & 2 & 3 & 1 \\
6 & 2 & 3 & 1 & 2 \\
7 & 3 & 1 & 3 & 2 \\
8 & 3 & 2 & 1 & 3 \\
9 & 3 & 3 & 2 & 1 \\
\hline
\end{tabular}

\subsection{Signal-to-noise ratio}

Using $\mathrm{S} / \mathrm{N}$ ratios may reflect differences in the quality of the experiment. When the upper cutting width of the laser decreases, the cutting quality increases. Therefore, using "smaller-the-better" characteristic, the $\mathrm{S} / \mathrm{N}$ ratio ( $\eta$ value) was defined as follows [12]:

$\eta=-10 \times \log \left(\frac{1}{r} \sum_{i=1}^{r} y_{i}^{2}\right)$

where $r$ and $y_{i}$ are the measurement number and value of the upper cutting width on the timber specimen. When the cutting depth of the laser increases, the cutting quality increases. Therefore, using "bigger-the-better" characteristic, the $\mathrm{S} / \mathrm{N}$ ratio ( $\eta$ value) was defined as follows [12]:

$\eta=-10 \times \log \left(\frac{1}{r} \sum_{i=1}^{r} \frac{1}{y_{i}^{2}}\right)$

where $r$ and $y_{i}$ are the measurement number and value of the cutting depth on the timber specimen. Tables 3 and 4 list the measured values and $\mathrm{S} / \mathrm{N}$ ratios; the measured values $\left(y_{i}\right)$ corresponding to the upper cutting width and cutting depth were calculated $\mathrm{S} / \mathrm{N}$ ratios using Eq. (1) and

Table 2 Control factors and levels

\begin{tabular}{lllll}
\hline Symbol & Control factor & Level 1 & Level 2 & Level 3 \\
\hline A & Laser power (W) & 25.6 & 27.2 & $28.8^{\mathrm{a}}$ \\
B & Auxiliary gas & No & Air & Nitrogen $^{\mathrm{a}}$ \\
C & Processing speed (mm/s) & $3^{\mathrm{a}}$ & 4 & 5 \\
D & Number of cuts (times) & $1^{\mathrm{a}}$ & 2 & 3 \\
\hline
\end{tabular}

${ }^{\text {a }}$ Original processing 
Fig. 1 Machining profile

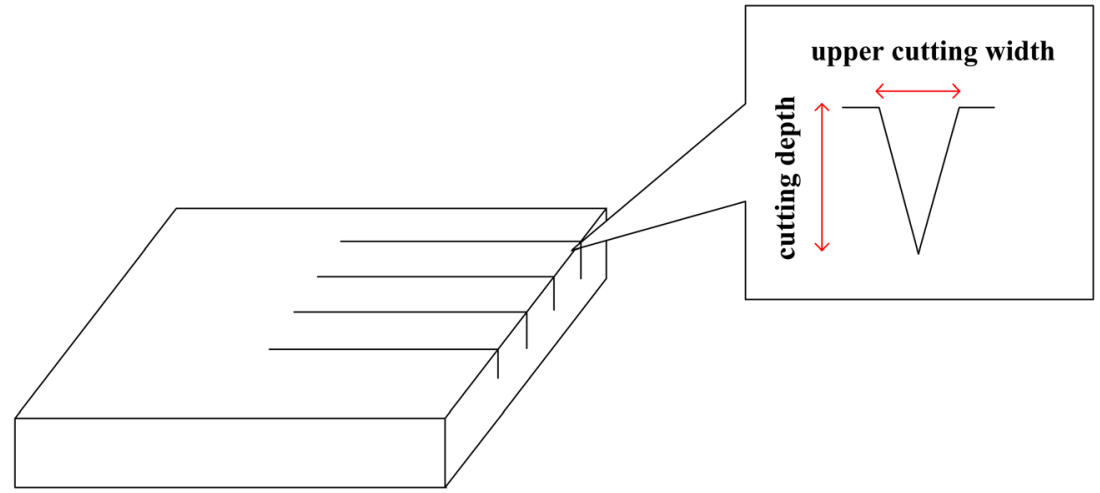

Table 3 Upper cutting width measured values and $\mathrm{S} / \mathrm{N}$ ratios

\begin{tabular}{llllllll}
\hline Experiment no. & \multicolumn{3}{l}{ Measured value $(\mathrm{mm})$} & & Average $(\mathrm{mm})$ & Standard deviation $(\mathrm{mm})$ & $\mathrm{S} / \mathrm{N}(\mathrm{dB})$ \\
\hline 1 & 0.84 & 0.82 & 0.83 & 0.81 & 0.83 & 0.01 & 1.67 \\
2 & 0.69 & 0.70 & 0.64 & 0.65 & 0.67 & 0.03 & 3.47 \\
3 & 0.62 & 0.62 & 0.62 & 0.61 & 0.62 & 0.01 & 4.19 \\
4 & 0.62 & 0.63 & 0.62 & 0.62 & 0.62 & 0.01 & 4.12 \\
5 & 0.56 & 0.58 & 0.57 & 0.57 & 0.57 & 0.01 & 4.88 \\
6 & 0.74 & 0.75 & 0.76 & 0.74 & 0.75 & 0.01 & 2.53 \\
7 & 0.72 & 0.73 & 0.72 & 0.71 & 0.72 & 0.01 & 2.85 \\
8 & 0.88 & 0.86 & 0.83 & 0.86 & 0.86 & 0.02 & 1.33 \\
9 & 0.72 & 0.71 & 0.73 & 0.72 & 0.72 & 0.01 & 2.84 \\
\hline
\end{tabular}

Eq. (2), respectively. Table 3 exhibits the upper cutting width values and $\mathrm{S} / \mathrm{N}$ ratios; experiment 5 exhibited the lowest average value and maximum noise ratio, whereas experiment 8 exhibited the highest average value and minimum noise ratio. Table 4 exhibits the cutting depth measured values and $\mathrm{S} / \mathrm{N}$ ratios; experiment 4 exhibited the highest average value and maximum noise ratio, whereas experiment 9 exhibited the lowest average value and minimum noise ratio.

In addition, each control factor had three levels; the difference between the highest $\mathrm{S} / \mathrm{N}$ ratio and the minimum noise level was called the level effect. The most critical factor of the level effect was calculated as follows:

Level $k_{p}=\frac{\sum \eta_{p_{k}}}{3}$

Level effect $\left.\right|_{p}=\left(\text { level } k_{p}\right)_{\max }-\left(\text { level } k_{p}\right)_{\min }$

where level $k_{p}$ is the effect of level $k(k=1,2$ and 3$)$ of factor $p$ ( $p=\mathrm{A}, \mathrm{B}, \mathrm{C}$ and $\mathrm{D}$ ), and $\eta_{p k}$ is the $\eta$ value of level $k$ of factor $p$. A greater level effect indicates a greater influence of the
Table 4 Cutting depth measured values and $\mathrm{S} / \mathrm{N}$ ratios

\begin{tabular}{llllllll}
\hline Experiment no. & \multicolumn{3}{l}{ Measured value $(\mathrm{mm})$} & & Average $(\mathrm{mm})$ & Standard deviation $(\mathrm{mm})$ & $\mathrm{S} / \mathrm{N}(\mathrm{dB})$ \\
\hline 1 & 3.10 & 3.09 & 3.03 & 3.07 & 3.07 & 0.03 & 9.75 \\
2 & 4.44 & 4.40 & 4.10 & 4.30 & 4.31 & 0.15 & 12.68 \\
3 & 4.50 & 4.50 & 4.70 & 4.60 & 4.58 & 0.10 & 13.20 \\
4 & 6.30 & 6.20 & 6.20 & 6.00 & 6.18 & 0.13 & 15.81 \\
5 & 2.27 & 2.34 & 2.29 & 2.26 & 2.29 & 0.04 & 7.19 \\
6 & 5.00 & 4.90 & 5.20 & 5.30 & 5.10 & 0.18 & 14.14 \\
7 & 5.60 & 5.10 & 5.40 & 5.30 & 5.35 & 0.21 & 14.55 \\
8 & 6.20 & 6.10 & 6.30 & 5.90 & 6.13 & 0.17 & 15.73 \\
9 & 1.91 & 1.92 & 1.88 & 1.93 & 1.91 & 0.02 & 5.62 \\
\hline
\end{tabular}


Table 5 Level effect of upper cutting width

\begin{tabular}{lllll}
\hline & A & B & C & D \\
\hline Level 1 & 3.11 & 2.88 & 1.84 & 3.13 \\
Level 2 & 3.84 & 3.23 & 3.48 & 2.95 \\
Level 3 & 2.34 & 3.19 & 3.97 & 3.21 \\
Level effect & 1.50 & 0.35 & 2.13 & 0.26 \\
Order & 2 & 3 & 1 & 4 \\
Significance & Yes & Yes & Yes & No \\
\hline
\end{tabular}

control factors. Table 5 and Fig. 2 display the level effect and response graph of the $\mathrm{S} / \mathrm{N}$ ratios of the upper cutting width. The most influential factors were processing speed (factor C), followed by laser power (factor A), auxiliary gas (factor B) and number of cuts (factor D). Because this study used "smaller-the-better" characteristic to determine the upper cutting width, the maximum $\mathrm{S} / \mathrm{N}$ ratios were considered, resulting in the optimal control factor level combination being $\mathrm{A}_{2} \mathrm{~B}_{2} \mathrm{C}_{3} \mathrm{D}_{3}$. Table 6 and Fig. 3 display the level effect and response graph of the $\mathrm{S} / \mathrm{N}$ ratios of the cutting depth. The most influential factors were number of cuts (factor D), followed by auxiliary gas (factor B), processing speed (factor $\mathrm{C}$ ) and laser power (factor A). Because this study used "bigger-the-better" characteristic to determine the cutting depth, the maximum $\mathrm{S} / \mathrm{N}$ ratios were considered, resulting in the optimal combination of control factors and levels being $\mathrm{A}_{2} \mathrm{~B}_{1} \mathrm{C}_{1} \mathrm{D}_{3}$.

\subsection{ANOVA}

The main purpose of the analysis of variance (ANOVA) is to identify the control factors affecting the quality characteristics. The formulae are as follows [13, 14]:

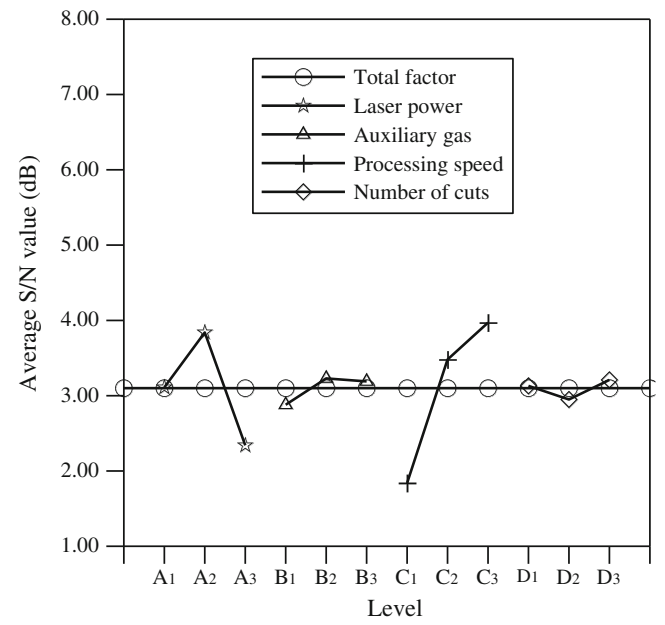

Fig. 2 Response graph of the $\mathrm{S} / \mathrm{N}$ ratios of the upper cutting width
Table 6 Level effect of cutting depth

\begin{tabular}{lllll}
\hline & A & B & C & D \\
\hline Level 1 & 11.88 & 13.37 & 13.21 & 7.52 \\
Level 2 & 12.38 & 11.87 & 11.37 & 13.79 \\
Level 3 & 11.97 & 10.99 & 11.65 & 14.92 \\
Level effect & 0.50 & 2.38 & 1.84 & 7.40 \\
Order & 4 & 2 & 3 & 1 \\
Significance & No & Yes & Yes & Yes \\
\hline
\end{tabular}

$\mathrm{SS}_{\mathrm{T}}=\sum \eta_{i}^{2}-\frac{\left(\sum \eta_{i}\right)^{2}}{9}$

$\mathrm{SS}_{p}=\frac{\sum \eta_{p k}^{2}}{3}-\frac{\left(\sum \eta_{i}\right)^{2}}{9}$

$\mathrm{SS}_{\mathrm{E}}=\mathrm{SS}_{\mathrm{T}}-\mathrm{SS}_{p}$

$V_{P}=\frac{\mathrm{SS}_{p}}{\mathrm{DOF}_{P}}$

$F_{p}=\frac{V_{p}}{V_{\mathrm{e}}}$

$Q_{p}=\frac{\mathrm{SS}_{p}-\mathrm{DOF}_{p} \times V_{\mathrm{e}}}{\mathrm{SS}_{\mathrm{T}}}$

where $S S_{\mathrm{T}}$ is the total sum of squares, $S S_{P}$ is the sum of squares of factor $P(P=\mathrm{A}, \mathrm{B}, \mathrm{C}$ and $\mathrm{D}), \eta_{i}$ is the $\mathrm{S} / \mathrm{N}$ ratio ( $i=1$ to 9 ) of each experiment, $\eta_{p k}$ is the $\mathrm{S} / \mathrm{N}$ ratio of level $k$ ( $\mathrm{k}=1,2$ and 3 ) of factor $P, V_{p}$ is the mean square of factor $P$, $\mathrm{DOF}_{P}$ are the freedom degrees of factor $P, F_{p}$ is the $F$ value of factor $P, V_{\mathrm{e}}$ is the mean square of pooled error and $Q_{p}$ is the quality contribution of factor $P$.

The $\mathrm{S} / \mathrm{N}$ ratios were calculated using Eqs. (1) to (4) (Tables 3 to 6), and the ANOVA of the upper cutting width

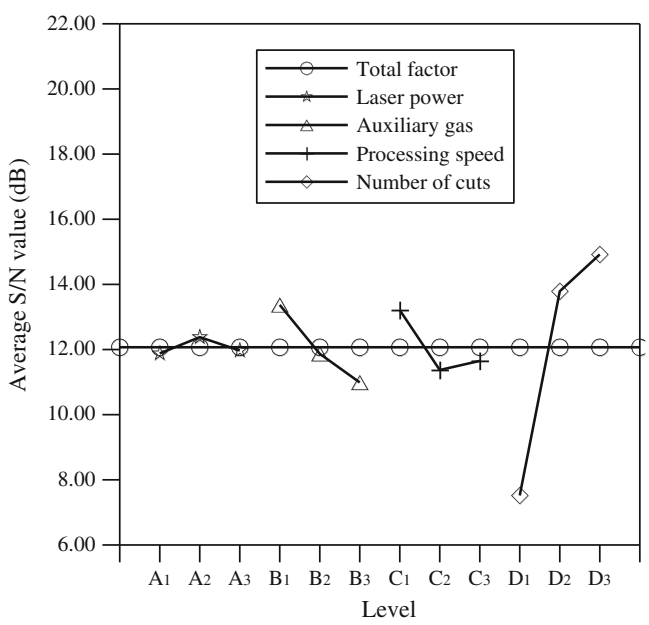

Fig. 3 Response graph of the $\mathrm{S} / \mathrm{N}$ ratios of the cutting depth 
Table 7 The ANOVA of upper cutting width

\begin{tabular}{llllll}
\hline Factor $(\mathrm{P})$ & $\begin{array}{l}\text { Degrees of freedom } \\
\left(\mathrm{DOF}_{\mathrm{P}}\right)\end{array}$ & $\begin{array}{l}\text { Sum of squares } \\
\left(\mathrm{SS}_{\mathrm{P}}\right)\end{array}$ & $\begin{array}{l}\text { Mean square } \\
\left(\mathrm{V}_{\mathrm{P}}\right)\end{array}$ & $\begin{array}{l}\mathrm{F} \text { value } \\
\left(\mathrm{F}_{\mathrm{P}}\right)\end{array}$ & $\begin{array}{l}\text { Contribution }\left(\mathrm{Q}_{\mathrm{P}}\right) \\
(\%)\end{array}$ \\
\hline $\mathrm{A}$ & 2 & 3.55 & 1.77 & 35.40 & 30.18 \\
$\mathrm{~B}$ & 2 & 0.24 & 0.12 & 24.00 & 1.22 \\
$\mathrm{C}$ & 2 & 7.54 & 3.77 & 75.40 & 65.09 \\
$\mathrm{D}$ & 2 & $0.10^{\mathrm{a}}$ & & & $(3.51)$ \\
$\begin{array}{l}\text { Pooled } \\
\text { error }\end{array}$ & $(2)$ & $(0.10)$ & $(0.05)$ & 100 \\
Total & 8 & 11.43 & & & \\
\hline
\end{tabular}

${ }^{\mathrm{a}}$ The sum of squares added together to estimate the pooled error sum of squares in parentheses and cutting depth was performed using Eqs. (5) to (10), as displayed in Tables 7 and 8. The ANOVA of the upper cutting width is summarised in Table 7; factor $\mathrm{C}$ was the most contribution factor $(65.09 \%)$, followed by factor A $(30.18 \%)$ and factor B $(1.22 \%)$. The ANOVA of the cutting depth is summarised in Table 8; factor D was the most contribution $(85.97 \%)$, followed by factor B $(7.50 \%)$ and factor C $(4.94 \%)$

\subsection{Optimal processing conditions}

By calculating the $\mathrm{S} / \mathrm{N}$ ratios and constructing the factor response tables, the most favourable combination of factor and levels for the upper cutting width was $\mathrm{A}_{2} \mathrm{~B}_{2} \mathrm{C}_{3} \mathrm{D}_{3}$, whereas that for the cutting depth was $\mathrm{A}_{2} \mathrm{~B}_{1} \mathrm{C}_{1} \mathrm{D}_{3}$. Table 9 lists the optimal control factor settings. The $\mathrm{S} / \mathrm{N}$ ratio and quality prediction of the optimal machining conditions can be calculated as follows:

Upper cutting width:

$$
\begin{gathered}
\eta_{\text {cal }}=\bar{T}+\left(\overline{A_{2}}-\bar{T}\right)+\left(\overline{B_{2}}-\bar{T}\right)+\left(\overline{C_{3}}-\bar{T}\right)+\left(\overline{D_{3}}-\bar{T}\right) \\
=\overline{A_{2}}+\overline{B_{2}}+\overline{C_{3}}+\overline{D_{3}}-\overline{3 T}
\end{gathered}
$$

$w_{\text {cal }}=10^{-\eta_{\text {cal }} / 20}$
Cutting depth:

$$
\begin{gathered}
\eta_{\text {cal }}=\bar{T}+\left(\overline{A_{2}}-\bar{T}\right)+\left(\overline{B_{1}}-\bar{T}\right)+\left(\overline{C_{1}}-\bar{T}\right)+\left(\overline{D_{3}}-\bar{T}\right) \\
=\overline{A_{2}}+\overline{B_{1}}+\overline{C_{1}}+\overline{D_{3}}-\overline{3 T}
\end{gathered}
$$

$D_{\text {cal }}=10^{\eta_{\text {cal }} / 20}$

where $\eta_{\mathrm{cal}}$ is the $\mathrm{S} / \mathrm{N}$ ratio of the optimal machining conditions, $\bar{T}$ is the average $\mathrm{S} / \mathrm{N}$ ratio of all control factors, $\overline{A_{2}}$ is the average $\mathrm{S} / \mathrm{N}$ ratio of factor $\mathrm{A}$ at level $2, \overline{B_{1}}$ and $\overline{B_{2}}$ are the average $\mathrm{S} / \mathrm{N}$ ratios of factor $\mathrm{B}$ at levels 1 and $2, \overline{C_{1}}$ and $\overline{C_{3}}$ are the average $\mathrm{S} / \mathrm{N}$ ratios of factor $\mathrm{C}$ at levels 1 and $3, \overline{D_{3}}$ is the average $\mathrm{S} / \mathrm{N}$ ratio of factor $\mathrm{D}$ at level 3 , $w_{\text {cal }}$ is the predictive value of the upper cutting width under optimal machining conditions and $D_{\text {cal }}$ is the predictive value of the cutting depth under optimal machining conditions. Equations (11) to (14) were used to obtain the $\mathrm{S} / \mathrm{N}$ ratios and the quality prediction of the optimal machining conditions (Table 10 ). The $\mathrm{S} / \mathrm{N}$ ratio of the optimal upper cutting width was $5.01 \mathrm{~dB}$, and the most favourable predictive value was $0.56 \mathrm{~mm}$. The $\mathrm{S} / \mathrm{N}$ ratio
Table 8 The ANOVA of cutting depth

\begin{tabular}{llllll}
\hline Factor $(\mathrm{P})$ & $\begin{array}{l}\text { Degrees of freedom } \\
\left(\mathrm{DOF}_{\mathrm{P}}\right)\end{array}$ & $\begin{array}{l}\text { Sum of squares } \\
\left(\mathrm{SS}_{\mathrm{P}}\right)\end{array}$ & $\begin{array}{l}\text { Mean square } \\
\left(\mathrm{V}_{\mathrm{P}}\right)\end{array}$ & $\begin{array}{l}\mathrm{F} \text { value } \\
\left(\mathrm{F}_{\mathrm{P}}\right)\end{array}$ & $\begin{array}{l}\text { Contribution }\left(\mathrm{Q}_{\mathrm{P}}\right) \\
(\%)\end{array}$ \\
\hline $\mathrm{A}$ & 2 & $0.43^{\mathrm{a}}$ & & & \\
$\mathrm{B}$ & 2 & 8.71 & 4.35 & 19.77 & 7.50 \\
$\mathrm{C}$ & 2 & 5.89 & 2.95 & 13.41 & 4.94 \\
$\mathrm{D}$ & 2 & 95.24 & 47.62 & 216.45 & 85.97 \\
Pooled & $(2)$ & $(0.43)$ & $(0.22)$ & & $(1.59)$ \\
$\quad$ error & & 110.27 & & & 100 \\
\hline
\end{tabular}

${ }^{\mathrm{a}}$ The sum of squares added together to estimate the pooled error sum of squares in parentheses 
Table 9 Optimal control factor settings

\begin{tabular}{llllll}
\hline Upper cutting width & Symbol & $\mathrm{A}_{2}$ & $\mathrm{~B}_{2}$ & $\mathrm{C}_{3}$ & $\mathrm{D}_{3}$ \\
& Data & $27.2(\mathrm{~W})$ & $\mathrm{Air}$ & $5(\mathrm{~mm} / \mathrm{s})$ & 3 (times) \\
Cutting depth & Symbol & $\mathrm{A}_{2}$ & $\mathrm{~B}_{1}$ & $\mathrm{C}_{1}$ & $\mathrm{D}_{3}$ \\
& Data & $27.2(\mathrm{~W})$ & $\mathrm{No}$ & $3(\mathrm{~mm} / \mathrm{s})$ & 3 (times) \\
MPCI & Symbol & $\mathrm{A}_{2}$ & $\mathrm{~B}_{1}$ & $\mathrm{C}_{3}$ & $\mathrm{D}_{3}$ \\
& Data & $27.2(\mathrm{~W})$ & $\mathrm{No}$ & $5(\mathrm{~mm} / \mathrm{s})$ & 3 (times) \\
\hline
\end{tabular}

variables (Figs. 5 and 6). The two input variables were equally divided into three fuzzy sets: $\mathrm{S}$ (small), $\mathrm{M}$ (medium) and $\mathrm{L}$ (large), comprising three levels. A fuzzy rule base is a type of the if-then combination of fuzzy rules, often used to express the system input and output relationship between inference and semantic rules, using Mamdani fuzzy rules [15]. The output variables used a triangular membership function to perform semantic fuzzy cutting (Fig. 7). The output variables in
Table 10 Optimal prediction and confirmation experiment results

\begin{tabular}{cllllll}
\hline Upper cutting Width & Experiment No. & $\operatorname{avg}(\mathrm{mm})$ & $\eta(\mathrm{dB})$ & $w_{\text {cal }}(\mathrm{mm})$ & $\eta_{\text {cal }}(\mathrm{dB})$ & $\mid \eta-\eta_{\text {cal }}(\mathrm{dB})$ \\
& 1 & 0.57 & 4.87 & 0.56 & 5.01 & 0.14 \\
& 2 & 0.58 & 4.78 & & & 0.23 \\
Cutting depth & Experiment No. & $\operatorname{avg}(\mathrm{mm})$ & $\eta(\mathrm{dB})$ & $D_{\text {cal }}(\mathrm{mm})$ & $\eta_{\text {cal }}(\mathrm{dB})$ & $\mid \eta-\eta_{\text {cal }}(\mathrm{dB})$ \\
& 1 & 6.72 & 16.55 & 6.81 & 16.66 & 0.11 \\
& 2 & 6.80 & 16.65 & & & 0.01 \\
\hline
\end{tabular}

of the optimal cutting depth was $16.66 \mathrm{~dB}$, and the most favourable predictive value was $6.81 \mathrm{~mm}$.

\subsection{Fuzzy logic system}

The multiple performance characteristics index (MPCI, Fig. 4) is used to identify the fuzzy inference process, which is a twoinput-one-output of the fuzzy logic system. The $\mathrm{S} / \mathrm{N}$ ratios of the upper cutting width (T1) and cutting depth (T2) were used as input variables in a fuzzy logic system and output variables for the MPCI (Y1), using the triangle membership function to perform the semantic fuzzy segmentation of these input

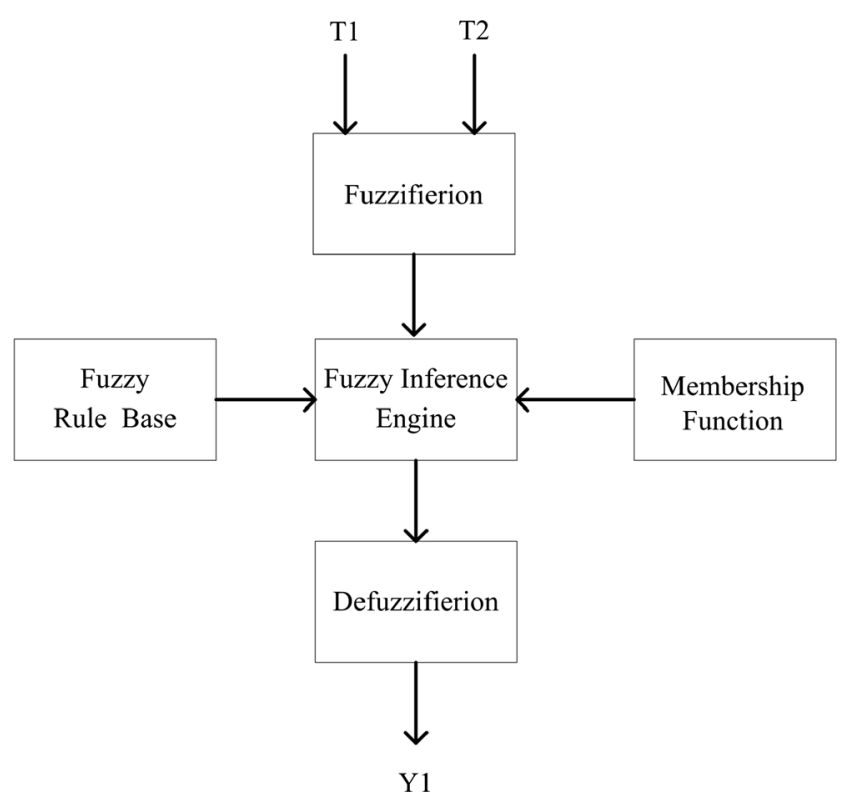

Fig. 4 Fuzzy logic system architecture the five fuzzy sets were divided into five categories: VS (very small), S (small), M (medium), L (large) and VL (very large). Two inputs with consistent quality characteristics were used; thus, nine fuzzy rules were developed (Table 11).

A fuzzy inference engine is a fuzzy system core; it can simulate the human decision-making to solve problems. This study used the Mamdani max-min fuzzy inference method. T1 and T2 were the input values in the fuzzy logic system; the fuzzy inference output of the membership function was expressed as follows:

$\mu_{\mathrm{C} 0}(y)=\left(\mu_{\mathrm{A} 1}\left(T_{1}\right) \wedge \mu_{\mathrm{B} 1}\left(T_{2}\right) \wedge \mu_{\mathrm{C} 1}(y)\right) \vee\left(\mu_{\mathrm{An}}\left(T_{1}\right) \wedge \mu_{\mathrm{Bn}}\left(T_{2}\right) \wedge \mu_{\mathrm{Cn}}(y)\right)$

where $\vee$ is the max fuzzy, and $\wedge$ is the min fuzzy. Finally, the centre of gravity method was used to solve the defuzzifierion; thus, the fuzzy inference output of the converter $\mu_{C 0}$ corresponded approximately to the output value $Y 1$.

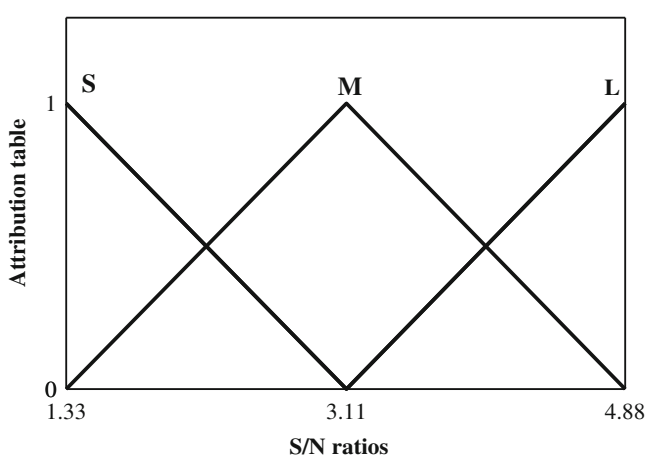

Fig. 5 Membership functions of upper cutting width 


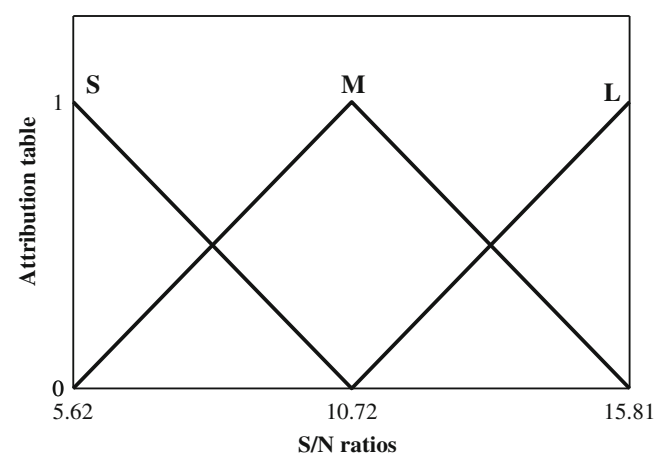

Fig. 6 Membership function of cutting depth

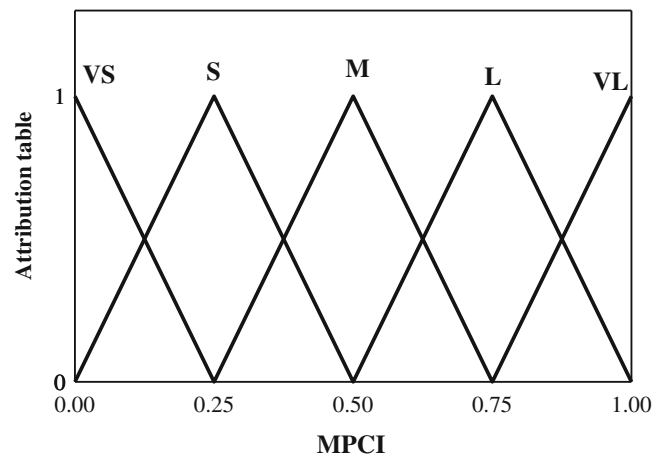

Fig. 7 Membership function of MPCI

$$
Y 1=\frac{\sum_{i=1}^{k} y_{i} \mu_{\mathrm{C} 0}\left(y_{i}\right)}{\sum_{i=1}^{k} \mu_{\mathrm{C} 0}\left(y_{i}\right)}
$$

where $\mu_{\mathrm{C} 0}\left(y_{i}\right)$ represents the $y_{i}$ (attribution values) of the fuzzy $C_{i}$ sets, namely the MPCI values. The inference results are listed in Table 12. Using the MPCI values in Table 12, each parameter from the level of the upper cutting width and cutting depth was calculated to determine the overall MPCI response (Table 13). High MPCI values are desirable. The optimal laser cutting parameters were as follows: laser power of $27.2 \mathrm{~W}$, no auxiliary gas added, processing speed of $5 \mathrm{~mm} / \mathrm{s}$ and number of cuts of three

Table 11 Fuzzy rules

\begin{tabular}{lllll}
\hline MPCI & & \multicolumn{3}{l}{ S/N of upper cutting width } \\
\cline { 2 - 5 } & & S & M & L \\
\hline S/N of cutting depth & S & VS & S & M \\
& M & S & M & L \\
& L & M & L & VL \\
\hline
\end{tabular}

Table 12 Results of MPCI

\begin{tabular}{llllllllll}
\hline No. & 1 & 2 & 3 & 4 & 5 & 6 & 7 & 8 & 9 \\
\hline MPCI & 0.30 & 0.61 & 0.67 & 0.79 & 0.59 & 0.56 & 0.62 & 0.49 & 0.25
\end{tabular}

Table 13 Responses of MPCI

\begin{tabular}{lllll}
\hline & A & B & C & D \\
\hline Level 1 & 0.53 & 0.57 & 0.45 & 0.38 \\
Level2 & 0.65 & 0.56 & 0.55 & 0.60 \\
Level 3 & 0.45 & 0.49 & 0.63 & 0.65 \\
Level effect & 0.2 & 0.08 & 0.18 & 0.27 \\
Order & 2 & 4 & 3 & 1 \\
Significance & Yes & No & Yes & Yes \\
\hline
\end{tabular}

times. The optimal level combination $\left(\mathrm{A}_{2} \mathrm{~B}_{1} \mathrm{C}_{3} \mathrm{D}_{3}\right)$ is shown in Table 9.

\section{Confirmation experiment}

\subsection{Confidence interval}

To verify the results, the optimal control factor settings listed in Table 9 were used in two replicate experiments, confirming the outcome shown in Table 10. When the optimal combination of factors of the upper cutting width was $\mathrm{A}_{2} \mathrm{~B}_{2} \mathrm{C}_{3} \mathrm{D}_{3}$, the averages were 0.57 and $0.58 \mathrm{~mm}$, and the $\mathrm{S} / \mathrm{N}$ ratios were 4.87 and $4.78 \mathrm{~dB}$. When the optimal combination of factors of the cutting depth was $\mathrm{A}_{2} \mathrm{~B}_{1} \mathrm{C}_{1} \mathrm{D}_{3}$, the averages were 6.72 and $6.80 \mathrm{~mm}$, and the $\mathrm{S} / \mathrm{N}$ ratios were 16.55 and $16.65 \mathrm{~dB}$.

Confidence intervals (CI) of $5 \%$ confidence band with the confirmatory number were calculated as follows [12]:

$\mathrm{CI}=\sqrt{F_{0.05 ; 2 ; v_{\mathrm{e}}} \times V_{\mathrm{e}} \times\left(\frac{1}{n_{\mathrm{eff}}}+\frac{1}{n_{\mathrm{ver}}}\right)}$

$n_{\mathrm{eff}}=\frac{n}{1+v}$

where $F_{0.05 ; 2 ; v_{\mathrm{e}}}$ represents an $F$ value for $95 \%$ confidence [13], $v_{\mathrm{e}}$ is the degrees of freedom for pooled error, $V_{\mathrm{e}}$ is the mean square of pooled error, $n_{\mathrm{ver}}$ is the number of repetitions in the confirmation experiment, $n$ is the total number of experiments and $v$ is the total main factor degrees of freedom.

Using Eqs. (17) and (18), the CI of the upper cutting width, obtained by processing timber with a $\mathrm{CO}_{2}$ laser, was $1.10 \mathrm{~dB}$, and the $\mathrm{CI}$ of the cutting depth was $2.31 \mathrm{~dB}$. The $\mathrm{CI}$ of the upper cutting width in the range 
Table 14 Results of optimal processing and original processing

\begin{tabular}{llll}
\hline & Combination of cutting conditions & Upper cutting width (mm) & Cutting depth (mm) \\
\hline Optimal processing & $\mathrm{A}_{2} \mathrm{~B}_{1} \mathrm{C}_{3} \mathrm{D}_{3}$ & 0.57 & 4.46 \\
Original processing & $\mathrm{A}_{3} \mathrm{~B}_{3} \mathrm{C}_{1} \mathrm{D}_{1}$ & 0.64 & 3.13 \\
Gain & & -0.07 & 1.33 \\
\hline
\end{tabular}

$\left|\eta-\eta_{\text {cal }}\right|$ was 0.14 and $0.23 \mathrm{~dB}$ (Table 10), being less than $1.10 \mathrm{~dB}$, and the $\mathrm{CI}$ of the cutting depths in the range $\left|\eta-\eta_{\text {cal }}\right|$ was 0.11 and $0.01 \mathrm{~dB}$ (Table 10), being less than $2.31 \mathrm{~dB}$. Therefore, this study determined and verified the optimal combination of control factors.

\subsection{Verification of multiple quality characteristics}

To verify the most favourable MPCI, the optimal control factors and original control factors were individually tested, and the results are displayed in Table 14. Using the optimal processing, the upper cutting width was $0.57 \mathrm{~mm}$, and the cutting depth was $4.46 \mathrm{~mm}$, whereas using the original processing, the upper cutting width was $0.64 \mathrm{~mm}$, and the cutting depth was $3.13 \mathrm{~mm}$. This indicates that the upper cutting width of the gain was reduced by $0.07 \mathrm{~mm}$, and the cutting depth was increased by $1.33 \mathrm{~mm}$. Therefore, using the MPCI enhanced the quality of the cut timber.

\section{Results and discussion}

Regarding the upper cutting width, the processing speed (factor C) was the most crucial factor, and its optimal value was $5 \mathrm{~mm} / \mathrm{s}$, because when the speed is too slow, excessive heat energy is absorbed per unit surface area, causing the upper cutting width to increase, which may result in scorching. The laser power had an optimal value of $27.2 \mathrm{~W}$, because if the power is too low, timber cannot be cut, but if the power is too high, timber may be scorched. Auxiliary gases include nitrogen and air. When nitrogen was used as an auxiliary gas, combustion was retarded because oxygen molecules were replaced with nitrogen molecules, making it difficult to cut the timber; however, when air was used, combustion was quickened, and the timber absorbed little heat and did not scorch. Finally, the number of cuts (factor D) did not exhibit considerable effects on the upper cutting width, but it was the most critical factor for the cutting depth, with repeated cuts resulting in a deeper cut. Regarding the cutting depth, the second most influential factor was the auxiliary gas, with the most favourable condition being not using any gas, because adding nitrogen resulted in difficulties during cutting as a result of the lack of oxygen for the combustion, whereas adding air resulted in a shallow cut. The processing speed was the third most influential factor for the cutting depth, with the optimal value being $3 \mathrm{~mm} / \mathrm{s}$, because slower speeds resulted in increased heat per unit area, increasing the cutting depth. Finally, the level changes of laser power did not substantially affect the cutting depth.

Regarding the MPCI, the most crucial factor was the number of cuts (factor D), because when timber was cut three times, the cutting depth increased. Nevertheless, this factor exhibited a negligible effect on the upper cutting width. The second most influential factor was the laser power, which had an optimal value of $27.2 \mathrm{~W}$, because if the laser power is too low, the timber cannot be cut, but if the power is too high, the timber may burn. The processing speed was the third most influential factor and had an optimal value of $5 \mathrm{~mm} / \mathrm{s}$, because if the speed is too low, the timber absorbs heat, and the upper cutting width increases, which may result in scorching; however, if the speed is too high, the resulting cut may be shallow. Nevertheless, the processing speed was more influential for the upper cutting width than for the cutting depth. Finally, the level changes of auxiliary gas did not substantially affect the cutting quality obtained with the MPCI.

\section{Conclusion}

The cutting width and depth in laser machining was analysed by fuzzy-based Taguchi methods. The hierarchy of process variables affecting cutting width and depth was established and allowed identifying the most favourable combination of factors. The optimal combination of control factors was $\mathrm{A}_{2} \mathrm{~B}_{1} \mathrm{C}_{3} \mathrm{D}_{3}$; the significant factors are the control factors in the order D (number of cuts), A (laser power), C (processing speed) and B (auxiliary gas).

Verifying sufficient width and depth is especially important in two viewpoints: the Fuzzy-based Taguchi method provides a systematic and efficient methodology for the laser machining of the multiple performance characteristics index. This study contributes to research artwork of complex graphics and when a small number of very expensive timbers are being machined. 
Open Access This article is distributed under the terms of the Creative Commons Attribution 4.0 International License (http:// creativecommons.org/licenses/by/4.0/), which permits unrestricted use, distribution, and reproduction in any medium, provided you give appropriate credit to the original author(s) and the source, provide a link to the Creative Commons license, and indicate if changes were made.

\section{References}

1. Subramonian IS (2010) Quality and performance analysis of $\mathrm{CO}_{2}$ laser machining. Lap Lambert Academic Publishing, Singapore

2. Juan Carlos HC, Huseyin KS, Lin L (2011) The effect of moisture content in fibre laser cutting of pine wood. Opt Lasers Eng 49(910):1139-1152

3. Panzner M, Wiedemann G, Henneberg K, Fischer R, Wittke T, Dietsch R (1998) Experimental investigation of the laser ablation process on wood surfaces. Appl Surf Sci 127-129:787-792

4. Lau WS, Yue TM, Lee TC, Lee WB (1995) Un-conventional machining of composite materials. J Mater Process Technol 48(1-4): 199-205

5. Samant AN, Dahotre NB (2008) Computational predictions in single-dimensional laser machining of alumina. Int $\mathrm{J}$ Mach Tools Manuf 48(12-13):1345-1353
6. Dubey AK, Yadava V (2008) Laser beam machining — a review. Int J Mach Tools Manuf 48(6):609-628

7. Hsieh KL, Tong LI, Chiu HP, Yeh HY (2005) Optimization of a multi-response problem in Taguchi's dynamic system. Comput Ind Eng 49(4):556-571

8. Lumley RM (1969) Controlled separation of brittle materials using a laser. Am Ceram Soc Bull 48:850-854

9. Lumley RM (1971) Initiation of a controlled fracture. US Patent 3: $610-871$

10. Tsai CH, Liou CS (2003) Fracture mechanism of laser cutting with controlled fracture. J Manuf Sci Eng-Trans ASME 125(3):519-528

11. Tsai CH, Chen CJ (2003) Formation of the breaking surface of alumina in laser cutting with a controlled fracture technique. Proc Inst Mech Eng Part B-J Eng Manuf 217(4):489-497

12. Ross PJ (1989) Taguchi techniques for quality engineering. McGraw Hill, New York

13. Montgomery DC (1985) Introduction to statistical quality control. Wiley, New York

14. Deng CS, Chin JH (2005) Hole roundness in deep-hole drilling as analysed by Taguchi methods. Int J Adv Manuf Technol 25:420 426

15. Zimmermann HJ (2001) Fuzzy set theory—and its applications. Kluwer Academic Publishers, Boston 